\title{
INTERATIVIDADE EM AMBIENTE VIRTUAL DE APRENDIZAGEM: CONTRIBUIÇÕES DE UMA EXPERIMENTAÇÃO
}

\author{
Vanessa Matos dos SANTOS ${ }^{1}$ \\ Maria Teresa Miceli KERBAUY ${ }^{2}$
}

\begin{abstract}
RESUMO: A relação existente entre o homem e a tecnologia - na qual os papéis de dominador e dominado estão constantemente sendo debatidos - a humanização da técnica é o componente capaz de garantir a apropriação social da tecnologia. Nesse sentido, esta humanização pode ser alcançada à medida que a tecnologia passa a transformar o processo da comunicação e, por conseguinte, passa a contribuir para o crescimento e desenvolvimento educacional do homem. Fala-se, portanto, em tecnologias comunicacionais - isto é, tecnologias que se prestam a facilitar o processo comunicacional entre os sujeitos. No âmbito da comunicação mediada, o computador e a internet, juntos, são capazes de permitir uma espécie de ambiência social mediada e, desta forma, também terminam por possibilitar que o homem experiencie a imersão num ambiente virtual de comunicação. Juntando-se às possibilidades oferecidas pelos ambientes virtuais a necessidade crescente de educação continuada no cenário da Sociedade Aprendente, forma-se o cenário de desenvolvimento dos Ambientes Virtuais de Aprendizagem (AVA). Conforme as tecnologias da informação e comunicação se desenvolvem, também os ambientes virtuais de aprendizagem avançam, pois incorporam o potencial tecnológico da sociedade. O presente artigo analisa, através dos estudos de interatividade, os comportamentos interacionais dos Sujeitos imersos num AVA como ponto de apoio para o desenvolvimento educacional.
\end{abstract}

PALAVRAS-CHAVE: Ambiente virtual de aprendizagem. Interação. Interatividade.

\section{Introdução}

A comunicação é, antes de tudo, uma interação entre sujeitos semelhantes. Não ocorre no sentido de um indivíduo somente, mas existe a interação criada entre os indivíduos. Isto é, o indivíduo se integra e passa a fazer parte da comunicação. Enquanto parte integrante do sujeito, a comunicação é essencial para vida em sociedade e, como tal, à medida que o homem se desenvolve esta também se transforma, juntamente com a técnica e a tecnologia do momento histórico. A técnica é traduzida como uma habilidade específica para se fazer algo (aptidões entendidas como intransferíveis, tal como no mundo grego) enquanto que a tecnologia visa à produção com base em processos lucrativos, reproduzíveis rapidamente.

A relação existente entre o homem e a tecnologia - na qual os papéis de dominador e dominado estão constantemente sendo debatidos - a humanização da técnica é o componente

\footnotetext{
${ }^{1}$ Doutoranda em Educação Escolar. UNESP - Universidade Estadual Paulista. Faculdade de Ciências e Letras Pós - Graduação em Educação Escolar - Araraquara - SP - Brasil. 14800-901 - vanmatos.santos@gmail.com

${ }^{2}$ UNESP - Universidade Estadual Paulista. Faculdade de Ciências e Letras - Campus de Araraquara. Araraquara - SP - Brasil. 14800-901 - kerbauy@travelnet.com.br
} 
capaz de garantir a apropriação social da tecnologia. Nesse sentido, esta humanização pode ser alcançada à medida que a tecnologia passa a transformar o processo da comunicação. Fala-se, portanto, em tecnologias comunicacionais - isto é, tecnologias que se prestam a facilitar o processo comunicacional entre os sujeitos.

Para cada momento histórico houve uma tecnologia comunicacional específica que traduzia o período, conforme as modificações da sociedade; inicialmente, o homem utilizouse da tecnologia do alfabeto, que alterou a sua maneira de estruturar pensamentos, seguida da tecnologia do livro, rádio, TV etc. até alcançarmos o computador e a internet na arquitetura de uma sociedade tecnológica. Castells (2002, p.108) esclarece que é necessário atentarmos para o fato de que estamos vivendo uma revolução tecnológica; porém “A primeira característica do novo paradigma é que a informação é sua matéria-prima: são tecnologias para agir sobre a informação, não apenas informação para agir sobre a tecnologia, como foi o caso das revoluções tecnológicas anteriores.”

O novo ambiente comunicacional digital obriga-nos a desenvolver novas linguagens e termina por propiciar novas formas de sociabilidade e aprendizagem. Uma vez inseridos no contexto da problemática, não conseguimos, por vezes, o distanciamento necessário a uma pesquisa científica, razão de nosso atraso no tocante a algumas questões contemporâneas, como as novas formas de comunicação e suas possibilidades nos mais variados campos do saber.

Nas palavras de Dominique Wolton (2003, p.33), o que realmente se verifica é a “evolução do modelo cultural de comunicação”, ou seja, as mudanças não ocorrem, necessariamente, segundo a velocidade das novas tecnologias e sim, de acordo com a cultura em geral. Neste sentido, portanto, podemos destacar a iminência de novos paradigmas para entender o processo de comunicação na contemporaneidade. Para tanto, destacamos, por exemplo, o paradigma das redes de comunicação com a contrapartida cultural da cibercultura.

As modificações da sociedade refletem-se em todos os campos da vida cotidiana e da organização das atividades humanas, de forma que a comunicação - em seu aspecto social também sofre re-configurações, uma vez que se insere num contexto sócio-cultural mais amplo, traduzindo a interação homem - mundo. Esta interação homem-mundo pressupõe um tipo específico de comunicação, podendo esta segunda ser direta (face-a-face) ou mediada por algum suporte tecnológico (televisão, computador).

No âmbito da comunicação mediada, o computador e a internet, juntos, são capazes de permitir uma espécie de ambiência social mediada e, desta forma, também terminam por possibilitar que o homem experiencie a imersão num ambiente virtual de comunicação. 
Juntando-se às possibilidades oferecidas pelos ambientes virtuais a necessidade crescente de educação continuada no cenário da Sociedade Aprendente, forma-se o cenário de desenvolvimento dos Ambientes Virtuais de Aprendizagem (AVA). Estes ambientes são também chamados de plataformas de ensino a distância, vez que são usados nos mais variados tipos de projetos envolvendo educação ${ }^{3}$ a distância. Conforme as tecnologias da informação e comunicação se desenvolvem, também os ambientes virtuais de aprendizagem avançam, pois incorporam o potencial tecnológico da sociedade.

Finalmente, o desenvolvimento dos AVA ampara-se nos processos de comunicação e seu sucesso depende da eficácia dos mesmos. O estudo minucioso desta questão pode revelar outras potencialidades das novas tecnologias e, conforme já exposto, novas formas de interação (sociabilidade), e novas formas de gerir o conhecimento e a informação baseadas em um media. Trata-se, pois, de um novo paradigma para o estudo da comunicação midiática. Trata-se do que André Lemos (2004) chama de paradigma de redes, típico da cibercultura. O imaginário da cibercultura possibilita uma nova maneira de estruturação do pensamento e ordenação da informação e conhecimento. Kenski (2008) afirma que é praticamente impossível dissociar educação e comunicação, porque as novas tecnologias são capazes de promover - e em muitos aspectos até suscitar - novos saberes.

O suporte tecnológico - aqui traduzido como AVA - propicia que ensino possa ser mediado por uma máquina e a questão da interatividade ganha especial importância, vez que diminui a possível sensação de isolamento e favorece a troca de experiências multiculturais. As propriedades interativas do canal (e também ambiente) comunicacional é que vão determinar o grau de interatividade por eles proporcionados. Além do mais, a interatividade garante a rapidez das respostas dos professores ou tutores às dúvidas dos alunos e vice-versa (feedback), fazendo com que o aluno consiga progredir mais rapidamente.

Porém, para que projetos desta natureza possam ser implementados, torna-se necessário o desenvolvimento de experimentações científicas - e, neste sentido, este artigo configura-se como uma experiência piloto com o uso de AVA na disciplina "Teorias da

\footnotetext{
${ }^{3}$ Optou-se aqui pela terminologia Ensino a Distância em detrimento de Educação a Distância por conta da diferença que deve ser considerada entre educação e ensino. De acordo com Fétizon e Minto (2008), o conceito de educação é mais abrangente do que o de ensino: a educação é um processo social que se relaciona ao instrumental de que o grupo humano dispõe para promover a autoconstrução da humanidade de seus membros; enquanto que o conceito de ensino diz respeito à forma sistematizada, organizada e didaticamente estruturada com vistas à seleção de conteúdos e métodos - de trabalho pedagógico, que é adotada com o objetivo de disponibilizar, a todos os membros da sociedade, as informações, os conhecimentos e as teorias que já compõem um acervo de saberes que, por sua vez, é patrimônio da humanidade. $\mathrm{O}$ ato de ensinar está, portanto, contido no ato de educar, sendo este último um conceito mais amplo.
} 
Comunicação” do Programa de Pós-Graduação em Comunicação Midiática da Faculdade de Arquitetura, Artes e Comunicação (FAAC), Unesp, C. Bauru.

O Ambiente Virtual de Aprendizagem (AVA) utilizado na experimentação foi o TelEduc, desenvolvido pelo Instituto de Computação da Universidade Estadual de Campinas (UNICAMP), em razão da sua qualidade, bem como a proximidade geográfica de suporte técnico. O TelEduc é um ambiente bastante intuitivo e, além de possuir uma interface amigável, também dispõe de uma função crucial para o desenvolvimento desta pesquisa: a ferramenta intermap (interaction map) que é capaz de construir, computacionalmente, mapas interacionais (sociogramas). O TelEduc desempenha aqui - basicamente - a função de ambiente virtual no interior do qual ocorrem as interações entre os sujeitos. Busca-se, como objetivo geral, compreender e analisar as interações ocorridas no AVA TelEduc, tendo por base o conceito de interatividade desenvolvido por Steuer (1993) e a classificação proposta por Sheizaf Rafaeli (1988).

\section{Analisando a interatividade em ambiente virtual de aprendizagem: contribuições de Rafaeli e Steuer}

As várias conceituações sobre o que vem a ser interatividade privilegiam o modelo clássico emissor - mensagem - receptor. No caso do modelo aqui tratado, proposto por Sheizaf Rafaeli (1988), um componente é adicionado ao processo: o feedback. Isto ocorre, em especial porque, na visão do autor, os avanços nas ciências da comunicação, se considerados apenas pelo viés tecnológico, privilegiaram questões técnicas como, por exemplo, o aumento da largura de banda, ignorando por vezes o viés sociológico e comunicacional.

Para Van Dijk e De Vos (2000), a interação - ainda que seja freqüentemente trocada por interatividade - pode ser considerada uma parte especial da comunicação. Os autores seguem ressaltando a razão das inversões de termos:

In communication science the concept interaction - notably replaced by the term interactivity - is a special part of communication. Communication scientists are referring to forms and patterns of communication that are not interactive, such as the traditional press and broadcasting. This inversion can be explained by the adoption of the most common object of communication science: the study of communication means. Though it observes these means both in mediated and face-to-face communication, the prominence of media has always remained dominant in this discipline, particularly when it deals with interactivity. 
A origem do termo interatividade remonta do neologismo inglês interactivity e a massificação de seu uso se deu a partir dos anos de 1960 para denominar os avanços comunicacionais impulsionados pelo desenvolvimento da tecnologia computacional.

Embora tenha sido impulsionada pelas Novas Tecnologias da Informação e Comunicação (NTIC), a interatividade é muito anterior a elas. Rafaeli (1988) explica que a interação foi alvo de estudo da Sociologia e da Comunicação e era vista por alguns sociólogos, a exemplo de Bale (apud RAFAELI, 1988) e Goffman (apud RAFAELI, 1988), como um veículo através do qual a interação se tornava possível; assim as pessoas se envolviam em processos interacionais e, de acordo com tal pensamento, a comunicação era uma subdivisão da interação.

Com a comunicação subindo para o primeiro plano, a interação passou a ser uma subdivisão de uma área maior e novos estudos passaram adotar um outro foco no qual a comunicação figurava na centralidade do processo. Assim, Rafaeli (1988, p.116) explica que o estudo de processos de comunicação bilateral e reativa (estímulo) constitui-se em um verdadeiro fenômeno. No entanto, nenhum desses processos devem ser confundidos com interatividade. "Interactivity is even further advanced” e, como tal, um campo em estudo.

Do ponto de vista sociológico, no entanto, trata-se da potencialização da reciprocidade no processo comunicacional. Rafaeli (1988, p.116), explica que a reciprocidade não tem, necessariamente, um reflexo direto nas relações sociais: “This technical tit - for - tat reciprocity, however, does not have an obvious reflection on the social relations involved. Even taken together, the technological improvements should not be mistaken as providing or even regulating interactivity."

Uma vez que o avanço tecnológico também não deve ser compreendido como um possibilitador ou mesmo regulador da interatividade, então a essência do conceito em questão estaria na compreensão do modelo proposto pelo autor com base em três níveis de comunicação, sendo eles: comunicação bidirecional (two-way communication), comunicação reativa (reactive communication) e comunicação plenamente interativa (interactive communication). 


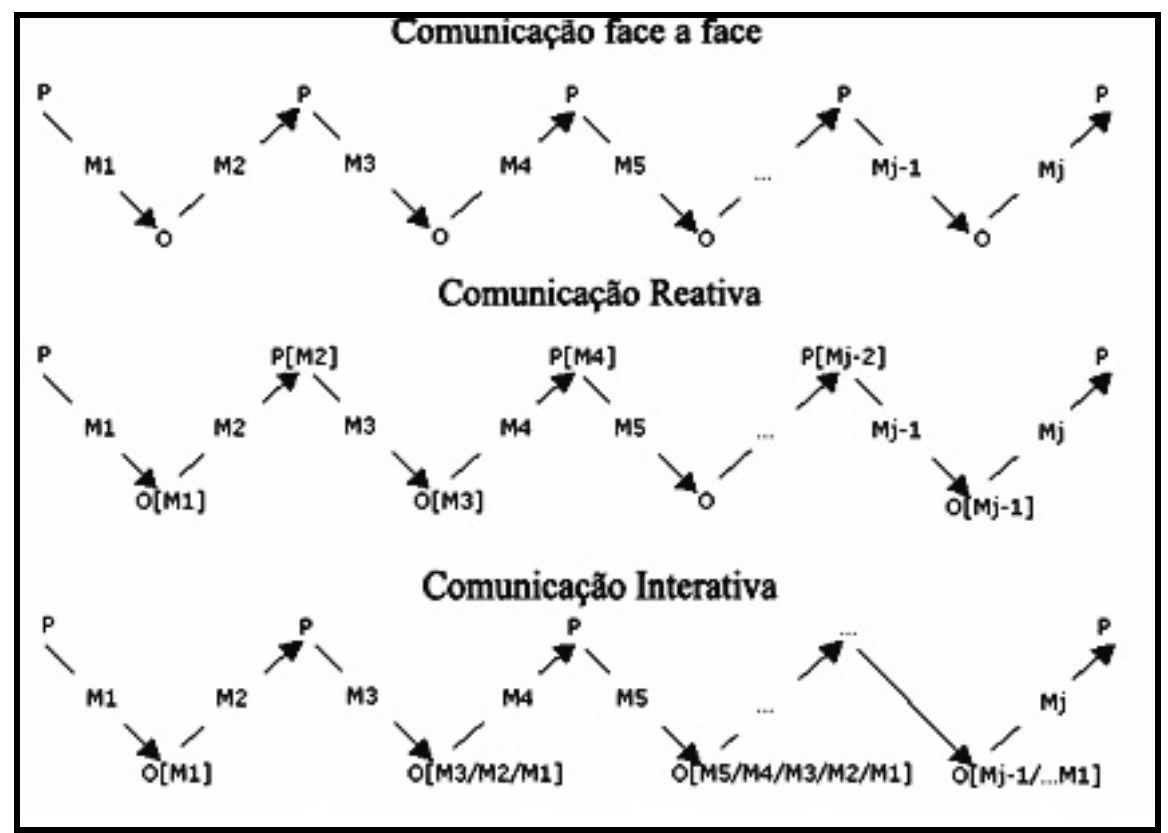

Figura 1 -Fluxo comunicacional de Rafaeli.

Fonte: Rafaeli (1988, p.120).

\section{Legenda}

$$
\begin{aligned}
& \mathrm{P}=\text { Sujeito A } \\
& \mathrm{O}=\text { Sujeito B } \\
& \mathrm{M} 1=\text { Mensagem } 1 \\
& \mathrm{M} 2=\text { Mensagem } 2 \\
& \mathrm{M} 3=\text { Mensagem } 3 \\
& \mathrm{M} 4=\text { Mensagem } 4 \\
& \mathrm{M} 5=\text { Mensagem } 5
\end{aligned}
$$

A primeira situação tratada por Rafaeli (1988) demonstra a comunicação face a face; neste modelo o Sujeito A (P) transmite uma mensagem (M1) para o Sujeito B (O), este último por sua vez a recebe e transmite uma mensagem (M2) para o Sujeito A (P) - sempre num processo contínuo.

A comunicação reativa, por sua vez, pressupõe que a mensagem (M1) emitida pelo Sujeito A (P) é incorporada pelo Sujeito B (O) que a elabora para, então, emitir outra mensagem (M2).

O processo da comunicação interativa, no entanto, pressupõe uma incorporação de mensagens anteriormente emitidas que vão se somando ao processo comunicativo, daí a razão da marcação M3/M2/M1. Isto é, houve uma incorporação das mensagens 1, 2 e 3 que resulta na emissão de uma mensagem 4 (nova) que, por sua vez, também será somada ao processo. 
Assim, a comunicação face a face pode ser reconhecida no fluxo unidirecional de transmissão de informação. A segunda, comunicação reativa exige, além da característica da primeira, também que as mensagens presentes refiram-se, ou seja, são coerentes com as mensagens anteriores. Isto é, deste modo ocorre uma reação a um estímulo.

Já a comunicação plenamente interativa difere da reativa porque, além de incorporar referenciais de conteúdo, natureza e formato, exige que a mensagem atual corresponda a uma seqüência de mensagens anteriores. Ou seja, trata-se de resgatar a seqüência da mensagem inicial. Aqui é possível fazer um resgate de Lévy (2000, p.80) para quem “[...] a possibilidade de apropriação e de personalização da mensagem recebida” é um ponto importante na determinação do nível de interatividade do dispositivo de comunicação em questão.

A interatividade pode ser explicitada, então, na concepção de Rafaeli (1988), no feedback que estabelece relações tanto com mensagens anteriores quanto com o trajeto que estas mesmas mensagens estabeleceram com outras que as precederam. É um processo contínuo de reapropriação e reaproveitamento da mensagem; somente o feedback por si não possibilita interatividade. E, neste sentido, nem toda reação é necessariamente feedback. A reação pressupõe uma resposta instantânea enquanto que o feedback pressupõe um processamento do estímulo para, então, emitir o retorno.

Para este estudioso, quando não há apropriação (e conseqüente reaproveitamento) da mensagem anterior pela posterior, então tudo o que houve foi reação a um estímulo. Isto é, existe aqui um resgate também da Teoria da Informação e, dentro dessa perspectiva, Rafaeli (1988, p.116-117) explica a interatividade: “In information theory terms, interactivity is all but noise; it relates to all the other components of the information transfer model - sender, receiver, channel, and message. Interactivity is potential adequacy, but it is up to the communicators to realize it."

Embora a prerrogativa de percepção dessa característica esteja a cargo de cada comunicador envolvido no processo, fica claro pela citação de Rafaeli (1988) que a interatividade estabelece conexão com todos os outros componentes do modelo teórico informacional - podendo ser o emissor (pessoa) ou, por exemplo, o canal (máquina).

A interatividade não significa necessariamente dupla via de comunicação (pressuposto do diálogo). Se assim fosse, o telefone seria o principal exemplo de meio de comunicação interativo, pois, permite o diálogo e a reciprocidade em tempo real, assim como acontece com videogames, hiperdocumentos e hipertextos. No entanto, no primeiro caso, a comunicação (e interação) se estabelece com uma pessoa enquanto que no segundo caso a mesma se dá com uma matriz de informações. Neste segundo caso, a interatividade é diferenciada porque, 
segundo Lévy (2000, p.80) remete ao "virtual”, a uma outra forma de estar, porém não estando.

Steuer (1992, p.6) explica que: "Presence is defined as the sense of being in an environment", enquanto que "Telepresence is defined as the experience of presence in an environment by means of a communication medium."

Isto é, a telepresença pode ser entendida como a experiência da presença mediada por um suporte comunicacional. Assim, a presença refere-se a percepção natural de um ambiente enquanto que a telepresença refere-se a uma percepção mediada do ambiente. Em síntese, a primeira situação remete ao físico enquanto que a segunda se desprende da materialidade para privilegiar os sentidos.

Com a telepresença é possível estar em um local (porque existe o sentimento e a percepção de que isto ocorre), estando fisicamente em outro lugar geográfico. Tal experiência se torna possível diante das possibilidades das mediações comunicacionais.

Na concepção de Steuer (1992), a interatividade, juntamente da vivacidade, é uma categoria formativa da telepresença. No entanto, alerta o autor: “[...] vividness and interactivity refer only to the representational powers of the technology”. Ou seja, tanto a vivacidade como a interatividade devem ser pensadas sob o ponto de vista da tecnologia.

Já a interatividade - nosso foco - se traduz, na concepção do Steuer (1992, p.14) como "Interactivity is defined as the extent to which users can participate in modifying the form and content of a mediated environment in real time”. É possível perceber aqui a convergência de idéias entre Lévy (2000) e Steuer (1992), ainda que o primeiro priorize o aspecto social da interatividade e o segundo adote como parâmetro o viés tecnológico. Para Steuer (1992, p.14) a interatividade “[...] é uma variável direcionada pelo estímulo e determinada pela estrutura tecnológica do meio de comunicação.” Em linhas gerais, a telepresença é um estágio tecnologicamente proporcionado para potencializar as ações humanas.

\section{Método}

Os estudos em ciências sociais são ainda muito recentes quando comparados às outras áreas do saber, fazendo com que muitas pesquisas sociais adquiram um caráter pioneiro. As transformações sociais resultantes da inserção das novas tecnologias da informação e comunicação no cotidiano também têm reflexos nas pesquisas científicas, de forma que pesquisas relacionadas à área das NTIC são, em sua grande maioria, consideradas pesquisas 
exploratórias. A pesquisa exploratória é, sobretudo, um estudo que visa contribuir com o desenvolvimento de trabalhos futuros na área. Exatamente por essa característica, abre espaço para o papel da interdisciplinaridade na tentativa de buscar explicações científicas para os fenômenos sociais recentes. A complexidade do momento atual não permite mais um olhar singular sobre a realidade; a pluralidade se faz necessária e urgente. Conforme a classificação proposta por Selltiz (1974, p.69), esta pesquisa é realizada sob a forma de uma experiência. O termo experiência, segundo a autora, não contempla os aspectos desta pesquisa. Os estudos de experiência fornecem um estudo das melhores práticas em determinado campo ou situação. “Sua utilidade decorre da apresentação de intuições e de práticas eficientes, e não da apresentação do ‘típico'.”

Esta pesquisa valeu-se da utilização de um Ambiente Virtual de Aprendizagem (AVA) para o estudo do processo de comunicação em ambiente virtual. O Ambiente Virtual de Aprendizagem (AVA) utilizado foi o TelEduc, desenvolvido pelo Instituto de Computação da Universidade de Campinas (UNICAMP), em razão da sua qualidade, bem como a proximidade geográfica de suporte técnico. O TelEduc desempenha aqui - basicamente - a função de ambiente virtual no interior do qual ocorrem as interações entre os sujeitos. Os sujeitos dessa experiência são alunos ingressantes no mestrado em comunicação midiática no ano de 2006, regularmente matriculados na disciplina Teorias da Comunicação ministrada na pós-graduação. Esse grupo de alunos foi submetido à experiência com o ambiente TelEduc para posterior análise do processo de comunicação ocorrido em ambiente virtual.

A coleta de dados para a experiência foi realizada através de duas técnicas: análise de interações no ambiente virtual e questionários (inicial e final). As interações ocorridas são analisadas, quantitativamente, com o auxílio de uma ferramenta do ambiente TelEduc denominada intermap (interaction map), que é capaz de construir, computacionalmente, mapas interacionais (sociogramas). A análise de sociogramas privilegia as interações em ambiente virtual. No entanto, cabe destacar a afirmação de Selltiz (1974, p.301) de que: "Fundamentalmente, a sociometria não é tanto um processo de coleta de dados quanto uma focalização em determinado tipo de assunto, e um método de análise ligado a esse assunto.”

Desta forma, será possível verificar quais foram as dificuldades encontradas pelos alunos e verificar se existe relação com as interações no ambiente virtual (através do Intermap). Busca-se, também, verificar se existe a comprovação da hipótese desta pesquisa de que as possibilidades interativas oferecidas pelo ambiente virtual ao sujeito e a interação entre os sujeitos contribui para melhorar e tornar mais efetiva a comunicação. 


\section{Apresentação dos Resultados}

Para a análise das interações ocorridas com o uso da ferramenta “fórum de discussão" do ambiente virtual de aprendizagem TelEduc foram selecionados quatro fóruns de discussão assim nomeados: "genealogias do virtual”, "grupo B”, “direitos à comunicação” e "pensar a comunicação”, escolhidos pela freqüência de participação dos componentes de seus grupos. Os resultados foram obtidos através da análise do fluxo de conversação registrados nos fóruns e encontram-se nas quatro tabelas:

Tabela 01 - Fluxos de comunicação do grupo “Genealogias do Virtual”

\begin{tabular}{|c|c|c|c|c|}
\hline Aluno & $\begin{array}{c}\text { Mensagem inicial } \\
\text { de um assunto }\end{array}$ & $\begin{array}{c}\text { Resposta de } \\
\text { mensagem inicial }\end{array}$ & $\begin{array}{c}\text { Mensagem de } \\
\text { segundo nível ou } \\
\text { comunicação } \\
\text { reativa }\end{array}$ & $\begin{array}{c}\text { Mensagem de } \\
\text { terceiro nível ou } \\
\text { comunicação } \\
\text { interativa }\end{array}$ \\
\hline Aluno X & 2 & $\mathbf{1}$ & 2 \\
\hline Aluno Y & $\mathbf{0}$ & $\mathbf{3}$ & $\mathbf{2}$ & 2 \\
\hline Aluno W & $\mathbf{1 0}$ & $\mathbf{6}$ & $\mathbf{3}$ & 3 \\
\hline Aluno Z & $\mathbf{1}$ & $\mathbf{2}$ & $\mathbf{1}$ & $\mathbf{1}$ \\
\hline
\end{tabular}

Tabela 02 - Fluxos de comunicação do grupo “B”

\begin{tabular}{|c|c|c|c|c|}
\hline Aluno & $\begin{array}{c}\text { Mensagem inicial } \\
\text { de um assunto }\end{array}$ & $\begin{array}{c}\text { Resposta de } \\
\text { mensagem inicial }\end{array}$ & $\begin{array}{c}\text { Mensagem de } \\
\text { segundo nível ou } \\
\text { comunicação } \\
\text { reativa }\end{array}$ & $\begin{array}{c}\text { Mensagem de } \\
\text { terceiro nível ou } \\
\text { comunicação } \\
\text { interativa }\end{array}$ \\
\hline Aluno A & 1 & $\mathbf{1}$ & $\mathbf{4}$ \\
\hline Aluno B & 1 & 3 & 2 & 1 \\
\hline Aluno C & 1 & 5 & 3 & 2 \\
\hline Aluno D & $\mathbf{0}$ & $\mathbf{5}$ & $\mathbf{0}$ & 1 \\
\hline Aluno E & 5 & 3 & 2 & 1 \\
\hline Aluno F & 1 & 2 & 2 & 0 \\
\hline
\end{tabular}

Tabela 03 - Fluxos de comunicação do grupo "Direitos à Comunicação"

\begin{tabular}{|c|c|c|c|c|}
\hline Aluno & $\begin{array}{c}\text { Mensagem inicial } \\
\text { de um assunto }\end{array}$ & $\begin{array}{c}\text { Resposta de } \\
\text { mensagem inicial }\end{array}$ & $\begin{array}{c}\text { Mensagem de } \\
\text { segundo nível ou } \\
\text { comunicação } \\
\text { reativa }\end{array}$ & $\begin{array}{c}\text { Mensagem de } \\
\text { terceiro nível ou } \\
\text { comunicação } \\
\text { interativa }\end{array}$ \\
\hline Aluno A & $\mathbf{0}$ & $\mathbf{2}$ & $\mathbf{2}$ & $\mathbf{0}$ \\
\hline Aluno B & $\mathbf{0}$ & $\mathbf{1}$ & $\mathbf{1}$ & $\mathbf{0}$ \\
\hline Aluno C & $\mathbf{1}$ & $\mathbf{0}$ & $\mathbf{0}$ & $\mathbf{0}$ \\
\hline Aluno D & $\mathbf{1}$ & $\mathbf{0}$ & $\mathbf{0}$ & $\mathbf{0}$ \\
\hline
\end{tabular}


Tabela 04 - Fluxos de comunicação do grupo "Pensar a comunicação"

\begin{tabular}{|c|c|c|c|c|}
\hline Aluno & $\begin{array}{c}\text { Mensagem inicial } \\
\text { de um assunto }\end{array}$ & $\begin{array}{c}\text { Resposta de } \\
\text { mensagem inicial }\end{array}$ & $\begin{array}{c}\text { Mensagem de } \\
\text { segundo nível ou } \\
\text { comunicação } \\
\text { reativa }\end{array}$ & $\begin{array}{c}\text { Mensagem de } \\
\text { terceiro nível ou } \\
\text { comunicação } \\
\text { interativa }\end{array}$ \\
\hline Aluno A & $\mathbf{2}$ & $\mathbf{0}$ & $\mathbf{0}$ & $\mathbf{0}$ \\
\hline Aluno B & $\mathbf{3}$ & $\mathbf{1}$ & $\mathbf{1}$ & $\mathbf{0}$ \\
\hline Aluno C & $\mathbf{0}$ & $\mathbf{1}$ & $\mathbf{1}$ & $\mathbf{0}$ \\
\hline
\end{tabular}

Nas tabelas 01, 02, 03 e 04 a mensagem inicial de assunto equivale à comunicação bidirecional (ou, neste caso, multidirecional, pois é emitida para todos os componentes do grupo), as respostas de mensagem inicial representam a soma das mensagens de segundo nível e mensagens de terceiro nível. Serão efetivamente interativas, segundo Rafaeli (1988), somente as mensagens de terceiro nível, vez que incorpora referenciais de conteúdo, natureza e formato e exige que a mensagem atual corresponda a uma seqüência de mensagens anteriores, formando um desenho similar a uma árvore e suas ramificações.

As tabelas 01 e 02 mostram fóruns nos quais pôde-se verificar a existência de comunicação interativa, isto é, a comunicação ocorrida entre os membros do grupo foi capaz de ultrapassar o nível reativo, o que é indicado pelo maior número de interações no sociograma (vide sociogramas 01 e 02). A mesma situação, no entanto, não pode ser verificada nas tabelas 03 e 04, pois nestes casos, a comunicação permanece somente no nível reativo da comunicação, o que pode ser verificado nas interações dos sociogramas, como pode ser verificado nos sociogramas 03 e 04. 


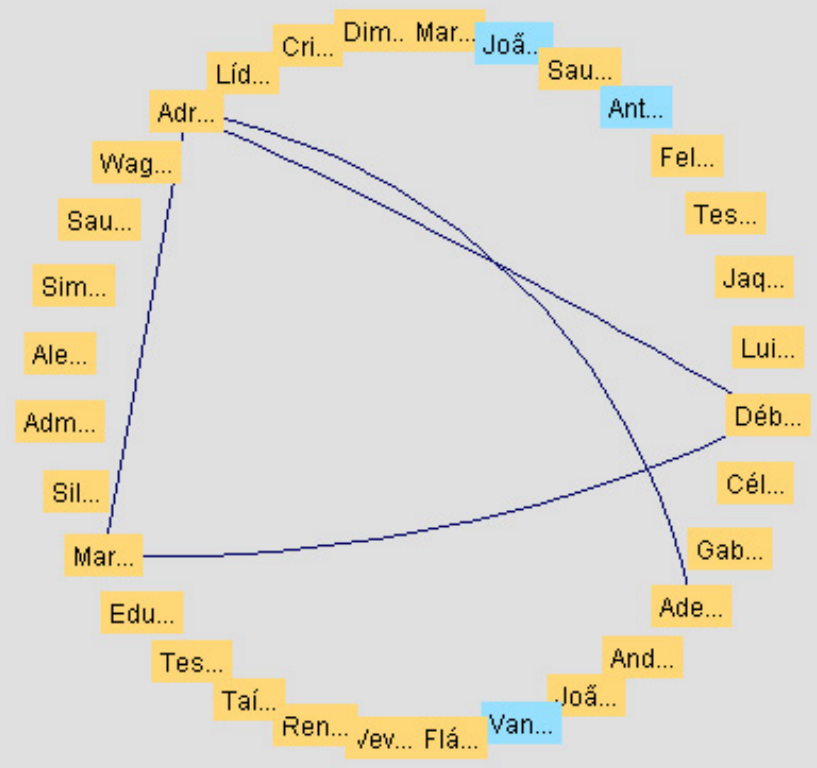

Sociograma 01 - Mapa das interações gerais ocorridas no grupo da tabela 04.

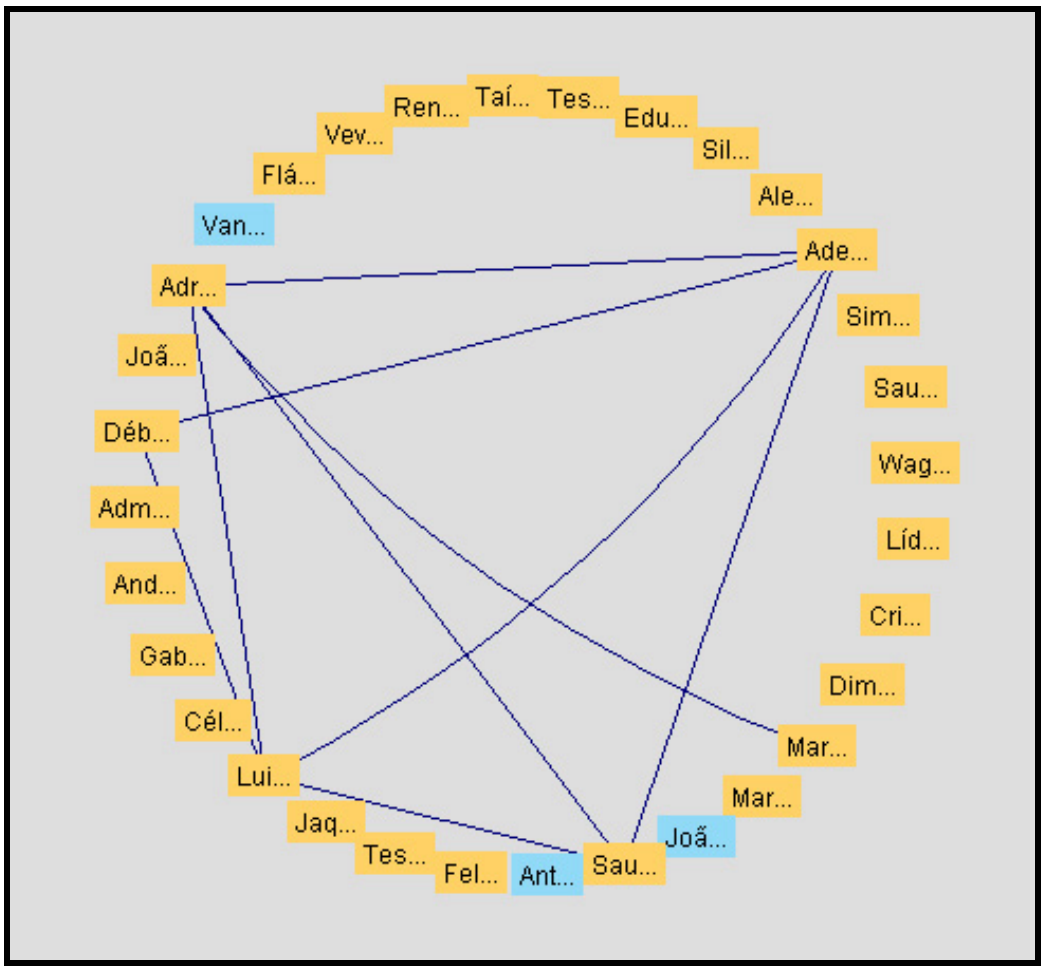

Sociograma 02 - Mapa das interações gerais ocorridas no grupo da tabela 05. 


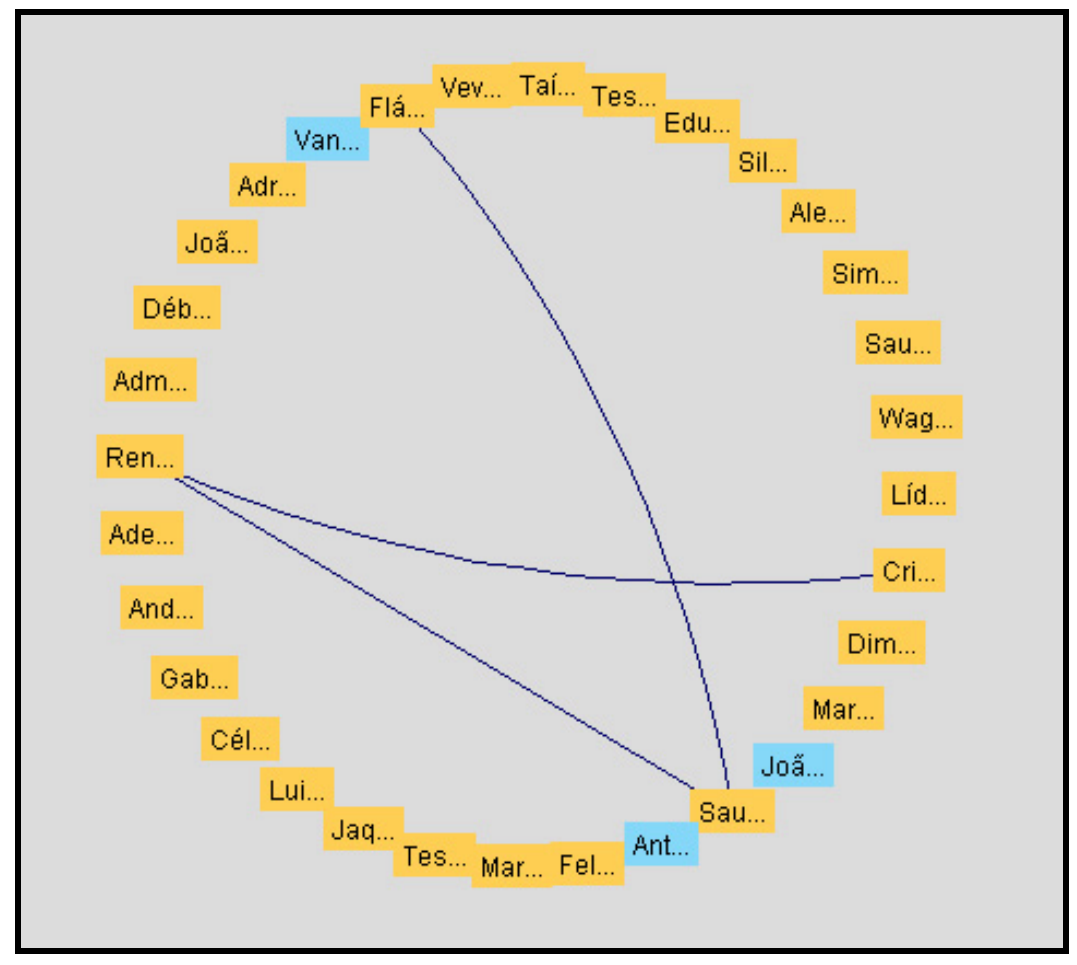

Sociograma 03 - Mapa das interações gerais ocorridas no grupo da tabela 06.

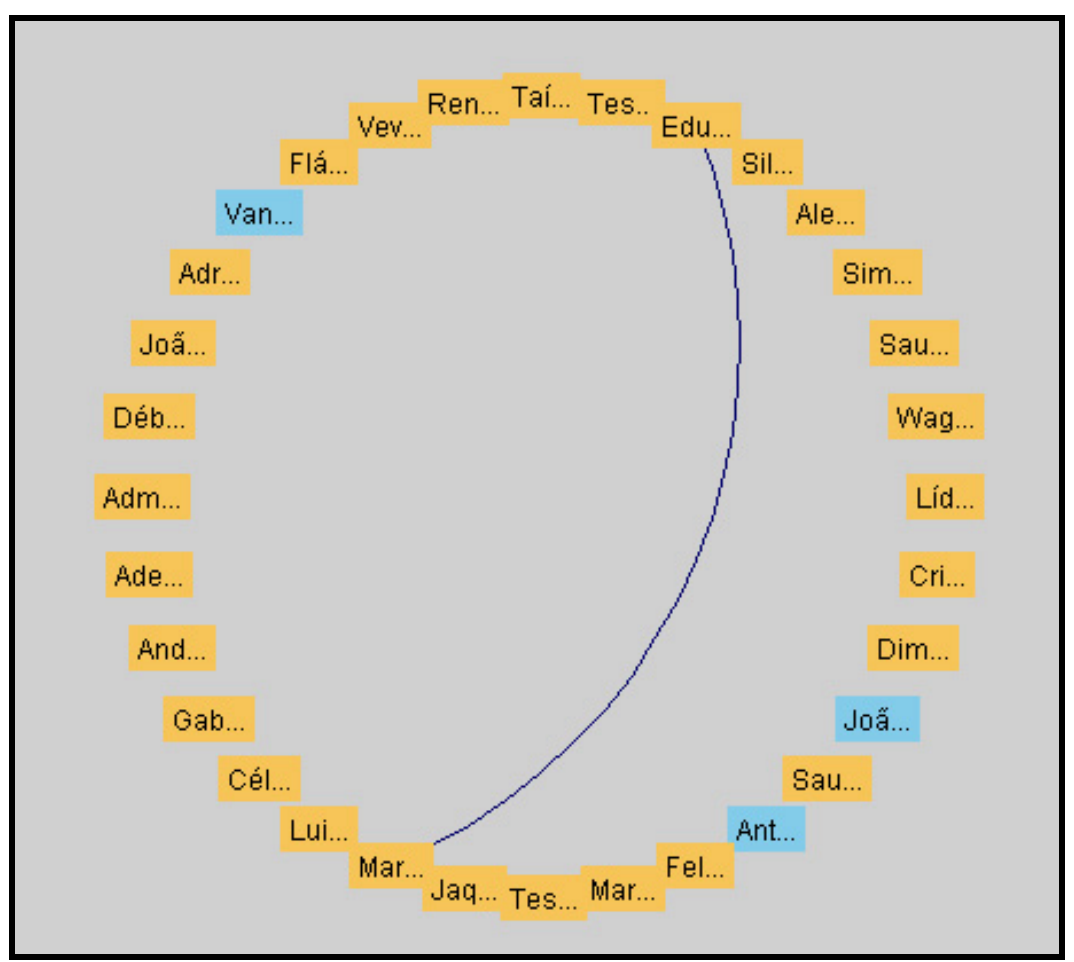

Sociograma 04 - Mapa das interações gerais ocorridas no grupo da tabela 07. 
É possível concluir que o ambiente virtual de aprendizagem TelEduc constitui-se num ambiente que explora as possibilidades oferecidas pelas redes telemáticas, sem no entanto, poder ser considerado totalmente interativo. No entanto, não se trata somente de contabilizar as mensagens ocorridas em algumas ferramentas que possibilitam interação no ambiente virtual. Mesmo porque, se para Rafaeli (1988) as mensagens é que merecem o título de interativas ou não, para autores como Lévy (2000), os meios de comunicação é que oferecem possibilidades consideradas mais ou menos interativas, decorrendo dessa constatação o termo mídias interativas.

Lévy (2000, p.82) explica que o grau de interatividade de uma mídia ou dispositivo de comunicação pode ser medido com base em eixos, sendo eles: possibilidades de apropriação e de personalização da mensagem, reciprocidade da comunicação, acesso à virtualidade, implicação da imagem dos participantes na mensagem e, o ponto máximo da interatividade: a telepresença. No âmbito do TelEduc podemos afirmar que o ambiente permitiu apropriação de mensagens, mas não necessariamente a personalização das mesmas. O canal e o desenho do curso permitiram que houvesse reciprocidade de comunicação, melhorando a disseminação informacional, pois o ambiente facilitava a emissão de mensagens do tipo todos - todos, o que favoreceu a interação em ambiente virtual, conforme podemos verificar no sociograma abaixo.

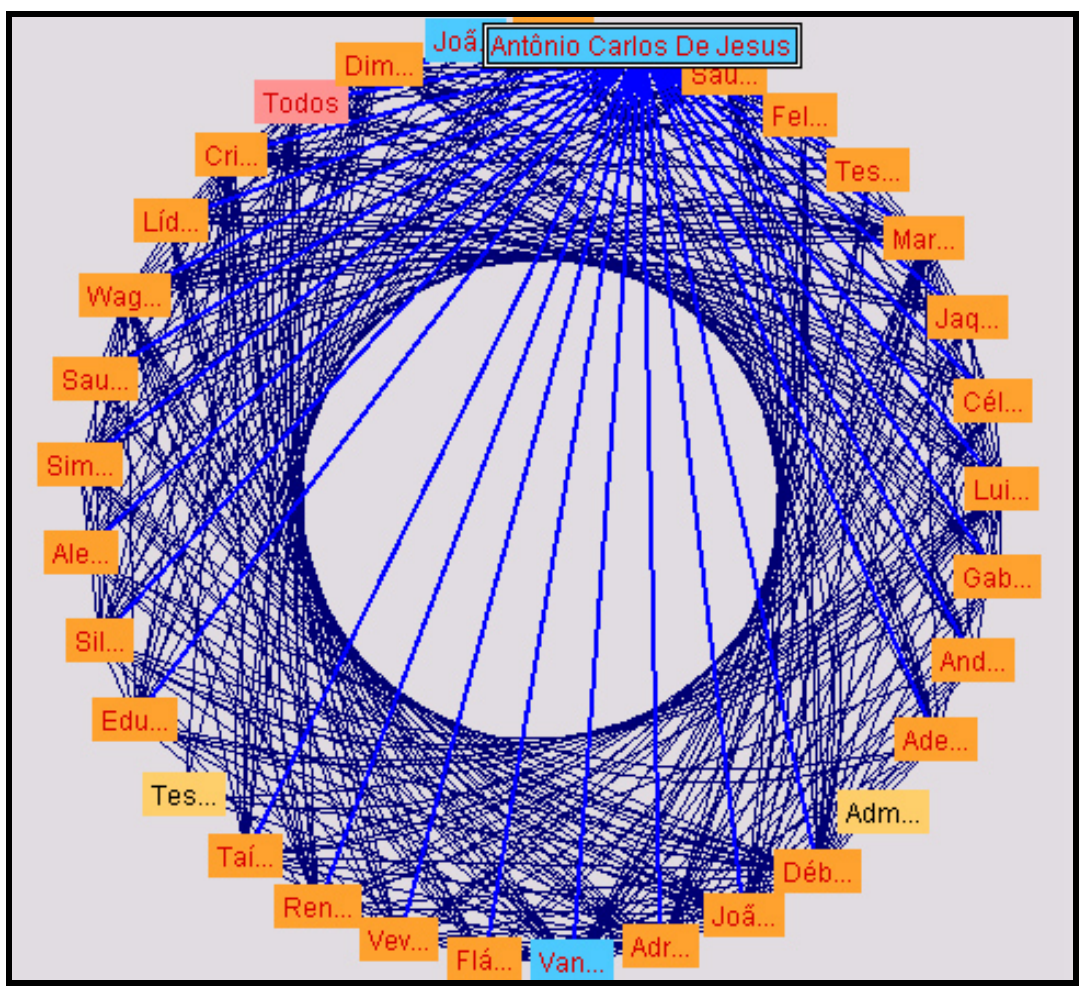


Sociograma 05 - Interações gerais com destaque para as mensagens emitidas pelo docente da disciplina "Teorias da Comunicação”.

O uso do ambiente em si já possibilita o acesso à virtualidade, ainda que esta ainda mereça ser re-pensada, vez que só configura como um desafio. A implicação de imagens também foi contemplada através da ferramenta Perfil na qual os alunos se apresentavam e anexavam suas fotos.

\section{Conclusão}

A emergência da virtualidade abre possibilidades novas de interação e interatividade, evitando o desânimo e a desmotivação. O esforço realizado por pesquisadores desta pesquisa em busca do entendimento do processo de comunicação nesse novo ambiente faz com que se lance mão da interdisciplinaridade, vez que uma única área do conhecimento não conseguiu explicar todos os fenômenos ocorridos. A virtualidade "palpável” possibilitada pela Internet traz para a cena a questão da sincronicidade do processo de comunicação mediada.

Com as tecnologias informacionais as oportunidades conectivas são ampliadas e o sujeito tem a possibilidade de dispor de um leque de informações. Aqui entra o papel do professor /orientador como um guia; cabe ao professor a tarefa de guiar os alunos às informações necessitadas nos momentos em que serão úteis, para propósitos específicos.

Através de ferramentas específicas (o portfolio, no caso do TelEduc), os AVA permitem que os alunos tenham a oportunidade de disponibilizar suas atividades para o grupo e também para o professor. É através desse compartilhamento de informações que se cria uma memória coletiva - fruto de uma atividade de construção informacional e conhecimento criado pelos próprios membros da comunidade. Por esta razão, a memória coletiva se destaca exatamente por sua característica mutável. Assim sendo, o ponto fundamental para o desenvolvimento da ambiência virtual (também nos AVA) é o estudo da dinâmica comunicacional, bem como dos espaços virtuais. A interface textual do ambiente virtual de aprendizagem TelEduc facilitou a navegação do aluno e possibilitou a interação nesse ambiente. No entanto, interação em ambiente virtual não significa, necessariamente, comunicação em ambiente virtual. Diferentes formas de interação pressupõem diferentes formas de comunicação. Em linhas gerais, a interatividade - pedagógica e comunicacional - é responsável pelo sucesso ou fracasso do processo de comunicação neste novo ambiente virtual. 
E, de fato, quanto maior a interação entre os sujeitos, melhor a comunicação. Se o sujeito não interage, consequentemente, não se comunica. A comunicação, por sua vez, é o elemento que conduz o indivíduo à autonomia. A base desta conclusão está nas freqüências de acesso ao ambiente virtual: os alunos que mais acessavam o ambiente foram os que apresentaram maiores índices de facilidade no decorrer da disciplina cursada através do AVA TelEduc e, quanto maior a facilidade, maior a autonomia do aluno em ambiente virtual. $\mathrm{O}$ desenvolvimento dos AVA está inserido neste momento histórico e é preciso desenvolver a autonomia aprendente.

As transformações alcançam a sala de aula tradicional e não há mais espaço para aspectos retrógrados, ou estaremos comprometendo nosso próprio desenvolvimento. No entanto, a interatividade, em consonância com Steuer (1992) e conforme pudemos verificar nesta experimentação, traduz-se apenas em um estágio tecnologicamente proporcionado pelas novas mídias. Sem dúvida, oferece novas possibilidades em todos os aspectos da vida, mas todas potencializadas pela ação do homem - que precisa caminhar constantemente em busca de melhores e mais eficientes formas de utilizar a tecnologia.

\section{INTERACTIVITY IN VIRTUAL LEARNING ENVIRONMENT: CONTRIBUTIONS OF AN EXPERIENCE}

ABSTRACT: The relationship between man and technology - in which the rules are constantly being discussed - the humanization of technology is the component that can guarantee the social appropriation of technology. This humanization may be achieved as the technology is transforming the communication process and, therefore, is to contribute to the growth and educational development of man. We talk, therefore, in communication technologies - ie technologies that lend themselves to facilitate the communication process between the subjects. In the context of mediated communication, computer and Internet are capable of allowing a kind of social environment mediated and thus also end up enabling the man may experience an immersion in a virtual environment for communication. Joining the possibilities offered by virtual environments, the growing need for continuing education in the setting of learning society, formed the setting for the development of Virtual Learning Environments (VLE). As information technology and communication develop, so the virtual learning environments advance, since they embody the technological potential of society. This article examines, through studies of interactivity, the interactional behavior of subjects immersed in VLE as a support for educational development.

KEYWORDS: Virtual learning environment. Interaction. Interactivity. 


\section{REFERÊNCIAS}

CASTELLS, M. A sociedade em rede. 6.ed. São Paulo: Paz e Terra, 2002.

FETIZON, B. A. M.; MINTO, C. A. Ensino a Distância: equívocos, legislação e defesa da formação presencial. Disponível em:

<www.adunesp.org.br/colegiados/2008/Artigo_EAD.pdf>. Acesso em: 10 nov. 2008.

KENSKI, V. M. Educação e tecnologias: o novo ritmo da informação. 3.ed. Campinas: Papirus, 2008.

LEMOS, A. As estruturas antropológicas do cyberespaço. Disponível em:

$<$ http://www.facom.ufba.br/pesq/cyber/lemos/estrcy1.html>. Acesso: 20 jun. 2008. Arquivo pessoal.

LÉVY, P. Cibercultura. São Paulo: Editora 34, 2000.

RAFAELI, S. Interactivity: from new media to communication. In: SAGE annual review of communication research: advancing communication science. Beverly Hills: Sage, 1988. v. 16, p. 110-134. Disponível: <http://gsb.haifa.ac.il/ sheizaf/interactivity/>. Acesso: 05 jan. 2009.

SELLTIZ, et. al. Métodos de pesquisa nas relações sociais. 7.ed. Tradução de Dante Moreira Leite. São Paulo: EPU, 1974. (Coleção Ciências do Comportamento).

STEUER, J. Defining virtual reality: dimensions determining telepresence. Journal of Communication, New York, v.42, n.4, p.72-93, 1992. Disponível em: <http://www.presenceresearch.org/papers/steuer92defining.pdf>. Acesso em: 15 jun. 2009.

VAN DIJK, J.; VOS, L. de. Searching for the Holy Grail: Images of Interactive Television. New Media and Society, Sage Publications. In: VOS, L. de. Searching for the holy grail: images of interactive television. Utrecht: University of Utrecht, 2000. Disponível em: <http://www.globalxs.nl/home/l/ldevos/itvresearch/total.pdf>. Acesso: 01 jul. 2009.

WOLTON, D. Internet, e depois? Porto Alegre: Sulina, 2003.

\section{BIBLIOGRAFIA CONSULTADA}

BARRETO, R. G. (Org.) Tecnologias educacionais e educação a distância: avaliando políticas e praticas. Rio de Janeiro: Quartet, 2001. 
BAUER, M. W.; GASKELL, G. Pesquisa qualitativa com texto, imagem e som: um manual prático. Tradução de Pedrinho A. Guareschi. Petrópolis: Vozes, 2002.

CASALEGNO, F. Exploring the notion of presence in collaborative environments. Revista Famecos, Porto Alegre, n.24, p.84-92, jul. 2004.

FRAGOSO, S. Interatividade. Disponível: <orion.lcg.ufrj.br/seminarios/interatividade.ppt> . Acesso em: 10 jul. 2008.

FREITAS, J. S. Interatividade nas mídias digitais: o uso de agentes inteligentes na comunicação eletrônica na internet. Dissertação. 2002. 134f. Dissertação (Mestrado em Comunicação e Cultura Contemporânea) - Faculdade de Comunicação, Universidade Federal da Bahia, Salvador, 2002.

HOFFMANN, W.A.M.; FURNIVAL, A. C. (Org.) Olhar: ciência, tecnologia e sociedade. São Carlos: Pedro e João Editores, 2008.

JOHNSON, S. Cultura da interface: como o computador transforma nossa maneira de criar e comunicar. Rio de Janeiro: Zahar, 2001.

KERBAUY, M. T. M.; BARROS, D. M. V. Inovação tecnológica: o virtual como novo espaço educativo. In: HOFFMANN, W. A. M.; FURNIVAL, A. C. (Org.) Olhar: ciência, tecnologia e sociedade. São Carlos: Pedro e João Editores, 2008. p.111-118.

KERCKHOVE, D. A pele da cultura: uma investigação sobre a nova realidade electrónica. Lisboa: Relógio D’Água, 1997.

KROKER, A. Code warriors. 1996. Disponível em: <http://www.ctheory.com/a36code_warriors.html>. Acesso: 05 jun. 2008.

LÉVY, P. As tecnologias da inteligência: o futuro do pensamento da era da informática. São Paulo: Ed. 34, 1993.

LOCKWOOD, F. Evaluación de las actividades incluidas em los textos. In: RODRÍGUEZ, E (Coord.). La educación a distancia en tiempos de cambio: nuevas generaciones, viejos y conflictos. Madrid: La Torre, 1999.

MAFFESOLI, M. A comunicação sem fim (teoria pós-moderna da comunicação). In: MARTINS, F. M.; SILVA, J. M. (Org.). A genealogia do virtual: comunicação, cultura e tecnologias do imaginário. Porto Alegre: Sulina, 2004.

MAIA, C. (Org.) Ead.br: experiências inovadoras em educação a distância no Brasil. São Paulo: Anhembi Morumbi, 2004. 
NIJHOLT, A. Where computers disappear, virtual humans appear. Disponível em: <www.sciencedirect.com>. Acesso: 19 dez. 2007.

PRIMO, A.; CASSOL, M. Explorando o conceito de interatividade: definições e taxonomia. Disponível em: <www.psico.ufrgs.br/ aprimo/pb/pgie.htm>. Acesso: 03 jun. 2008. 